\title{
Fermat: An Intelligent Social Network for Mathematics
}

\author{
María Lucía Barrón-Estrada, Ramón Zatarain-Cabada, Rosalío Zatarain-Cabada, \\ Jesús Armando Beltrán Verdugo, Franceli Linney Cibrian Robles, \\ and Marsia Irais Quiroz López \\ Instituto Tecnológico de Culiacán, Juan de Dios Bátiz s/n, Col. Guadalupe, \\ Culiacán Sinaloa, 80220, Mexico \\ \{lbarron, rzatarain\}@itculiacan.edu.mx, \\ \{armando.3eltran, Linney11\}@gmail.com, marcirais@hotmail.com
}

\begin{abstract}
We present Fermat, an Intelligent Social Network for Mathematics Learning, which integrates an Intelligent Tutoring System as an extra feature to help improve the teaching and learning process. The intelligent tutor takes into account both cognitive and affective factors, and by use of artificial intelligence techniques, provides users with a personalized and satisfying experience when taking the courses.
\end{abstract}

Keywords: Intelligent Tutoring Systems, social networks, neural networks, emotion recognition.

\section{Introduction}

Social Networks (SN) have a great impact on the daily lives of many people. In [7] the authors describe it as a structure of nodes that represent individual relationships (or organizations) among people of a certain domain. So, we can say that a social network is a dynamic interaction which allows sharing different types of files, comments and topics [3].

There are several types of social networks, which are distinguished according to the approach they have. For example, social learning networks, which use a collaborative environment and tools to help users in the learning process. Tools that can integrate social learning networks are Intelligent Tutoring Systems.

Intelligent Tutoring Systems (ITS) are computer programs that use many of resources to support the teaching and learning process. ITS must incorporate techniques of Artificial Intelligence (AI) and education, with the aim of creating a flexible and interactive environment that considers the different cognitive styles of students [11]. ITS should play an important role in monitoring both the learning the student has achieved, as well as identifying weaknesses, in order to find strategies that fit the student's cognitive style [11].

In order to reduce the problem of learning mathematics in Mexico middle schools, we built an intelligent social network for mathematics named Fermat [15]. Fermat contains an Intelligent Tutoring System whose main objective is to support the teaching-learning process in formal classroom education. 
This paper is organized as follows. In Section 2 we present a general architecture of Fermat. Section 3 gives information about the analysis and design of the social network. Section 4 explains how the ITS is structured. Section 5 will discuss some results and finally conclusions are presented in Section 6 .

\section{Fermat Architecture}

Learning Social Network Fermat has the basic functionalities in all social networks, but its main feature is that it includes an ITS that offers the course content in a personalized style to users, as shown in Figure 1.

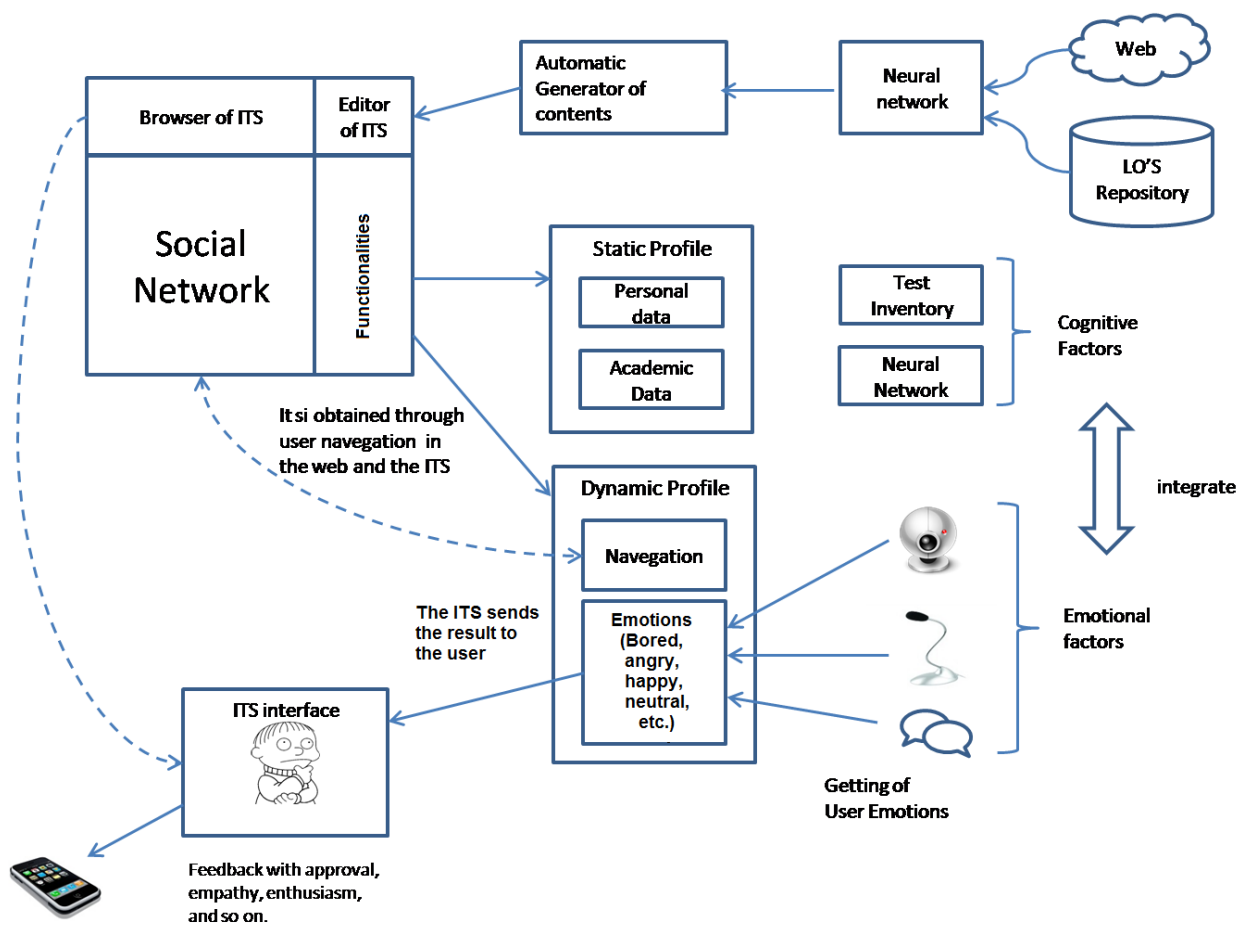

Fig. 1. Fermat Architecture

Users of the network are associated with personal, academic and affective information in a profile, which is obtained statically and dynamically. The static profile contains the initial information of the user (e.g. personal and academic information). The dynamic profile will be updated according to the user interaction within the network and the ITS, taking into account during this interaction, cognitive and emotional aspects.

According to [6], emotions are closely related to student learning, which in our point of view, represents a key factor to the student results.

Cognitive factors are obtained according to the history that we obtain from the results of examinations of the user and the learning style computed by the neural 
network. Emotional factors are obtained by sensors that are monitoring the user's emotions through facial expression and voice sound.

\section{Analysis and Design of Fermat}

In the analysis phase we determined the objectives and user requirements of the social network, which are fundamental to understanding the features needed by the user to interact and use the network.

These features provide a set of functional requirements that the network must have as well as quality requirements. Every functional requirement was developed in a use case to show how the user will interact with the system. We also developed a context diagram to show how the system interacts with external actors.

The design phase of the social network was divided in four main topics: data model, architecture, interfaces and components.

The system architecture was shown in figure 1, and some interfaces are presented in section 5. The components of the social network such as the editor and the browser, the user management, the learning objects, the collaboration of users in the network, and the adaptation of courses to a learning style, are directly related to achieving one of the primary functions of a social network, which is to enhance collaborative learning using an intelligent tutor system.

For the design of the interfaces we used the Mockup Builder tool [8].

\section{$4 \quad$ Fermat ITS}

The intelligent tutoring system (ITS) developed for the Fermat social network includes three main components (figure 2), which together are able to determine what the students know and how they are progressing, adjusting to their learning style needs [11].

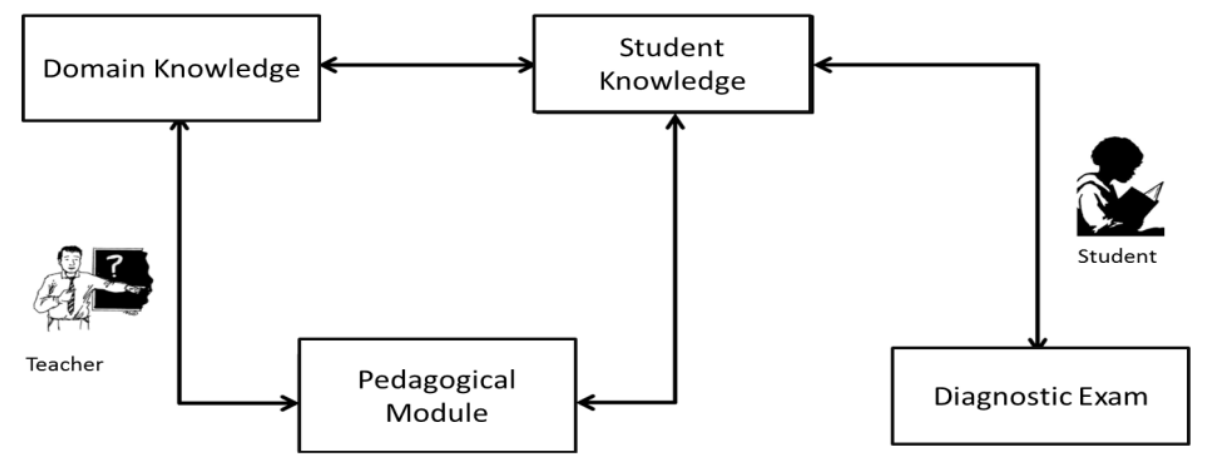

Fig. 2. General Architecture of the ITS. 
The three main components are:

1. Expert or Domain Knowledge Module.

2. Student Knowledge Module.

3. Tutoring or Pedagogical Module.

Domain knowledge Module: it is one that contains the description of knowledge on the subject of a particular domain, providing knowledge of what is taught to the student, so he can gain the skills and concepts required for meaningful learning. A course in Fermat can be seen as a tree diagram containing chapters and in turn these are made by subjects, as shown in Figure 3. The totality of all nodes in the tree represents the expert knowledge.

Student Knowledge Module: This module is responsible for assessing the student performance to determine his/her cognitive abilities and reasoning skills. It provides the information about what a student knows. This module is central to the module tutor in the selection of the learning style that better suits the user.

Fermat realizes what the student's knowledge is through a diagnostic test. The test results show what the student knows and what he needs to learn. The Fermat student module can be seen as a sub-tree of all knowledge possessed by the expert in the domain, as shown in the left part of figure 3. The representation is based on a model called "Overlay", where the student's knowledge is a subset of the expert knowledge. As the student uses the intelligent tutor he expands this subset [5].

Pedagogical Module: It represents the fundamental strategies for teaching the course content in Fermat. It is responsible for selecting the appropriate learning style and provides assistance to the student. For example, the tutor must know how to respond when the student cannot answer a question. In Fermat, the tutor module is based on the model developed by Felder and Silverman, which classifies the student preferences on four dimensions: perception, processing, input, and understanding [4].

On the other hand, we integrated another module to recognize the emotional states of students. Emotions are detected by means of the expression of the face and by the voice.

The method used for the detection of visual emotions is based on Ekman's theory [13], which recognizes ten emotions: anger, disgust, fear, happiness, sadness, surprise, well, bored, tired, neutral. To determine the emotion, the system take a picture of the student's face, sending the image file into a module to be transformed to a more basic form. Based on this picture we get the feature points that minimize the set of input data to the neural network. We use a Kohonen Neural network with 20 X20 input neurons and 2 output one is representing the emotion.

For the detection of emotions in the voice, this is captured primarily through the computer microphone and then normalized. Then we apply the technique to characterize components analysis (PCA) to the signal representing the voice. After using the SFFS method [14] we obtain an optimal set of features that will feed the neural network.

In Figure 4, we can see how we integrate the visual and sound emotions using a neural network. Having recognized the emotion, this is sent to the intelligent tutor to respond based on the emotion. 


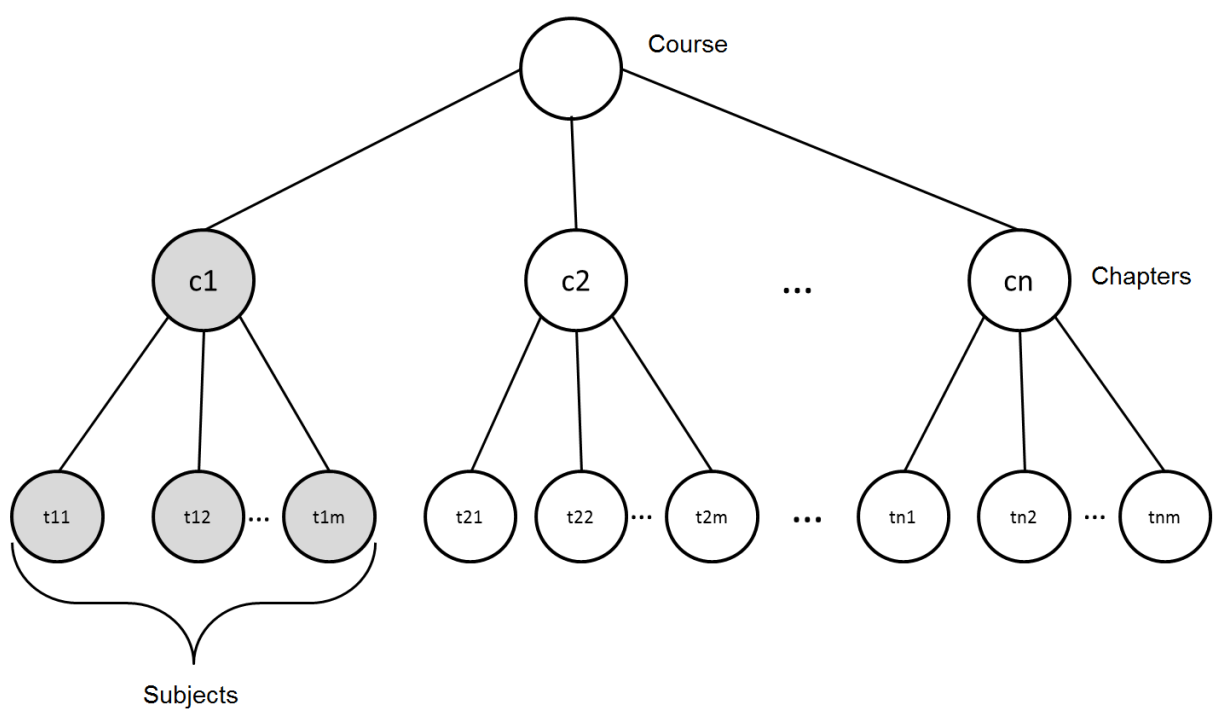

Fig. 3. Basic structure of a Fermat course.

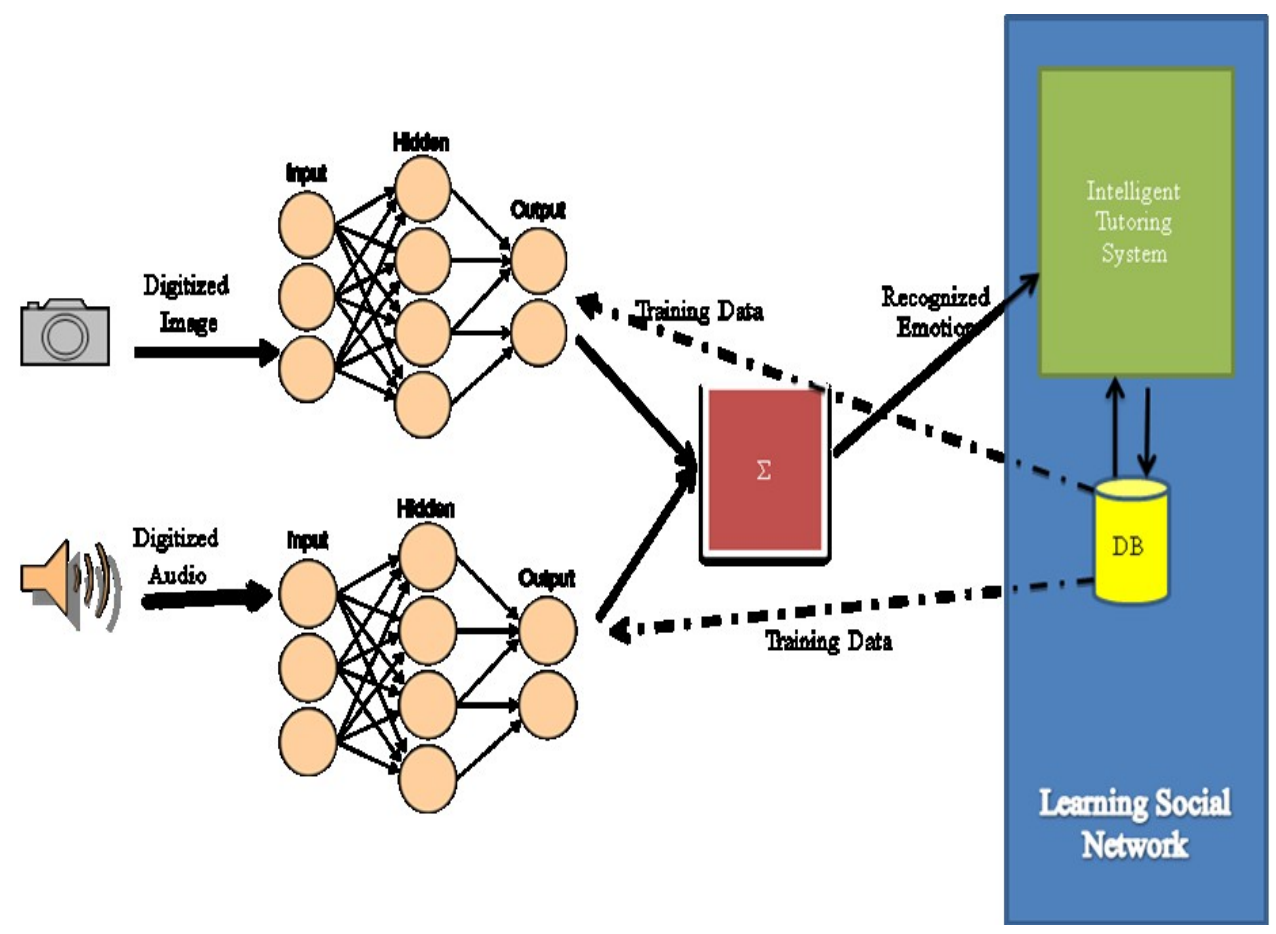

Fig. 4. Emotion recognition. 


\section{$5 \quad$ Fermat Testing}

Fermat was tested with primary school students in third grade. During this period we constantly supervised the use of the social network by the students and the teacher.

First, users tested the common functionality in the network such as: edit your profile, add friends and send messages. A teacher created a learning community, and added his students as members. The teacher also created a course as is shown in figure 5 .

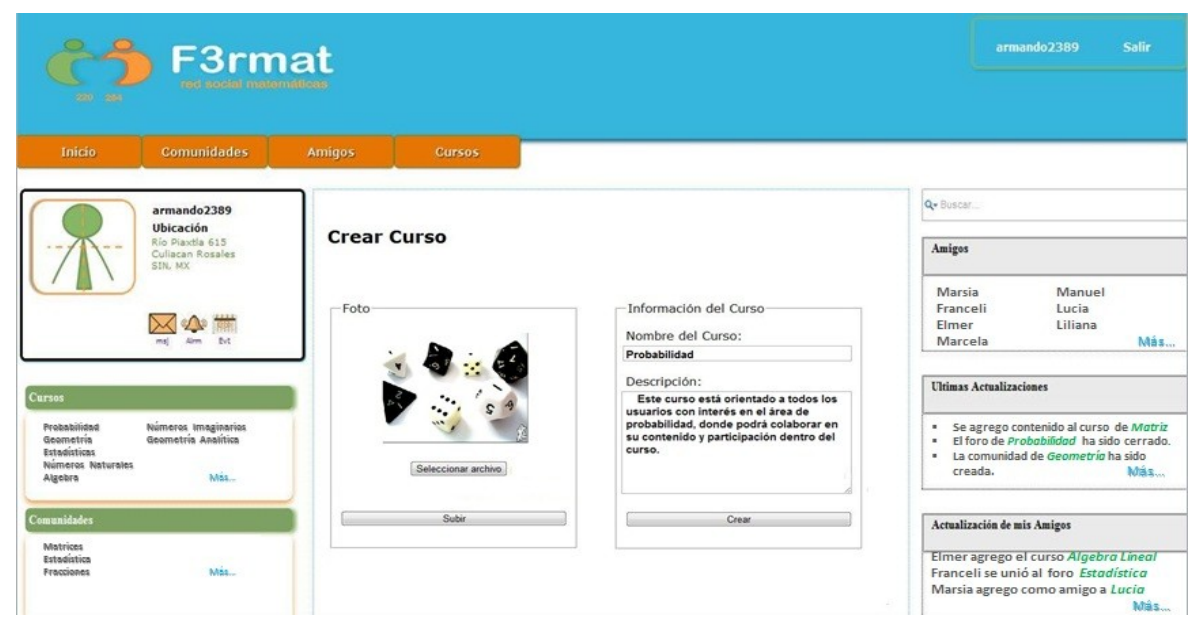

Fig. 5. Creation of a course in Fermat.

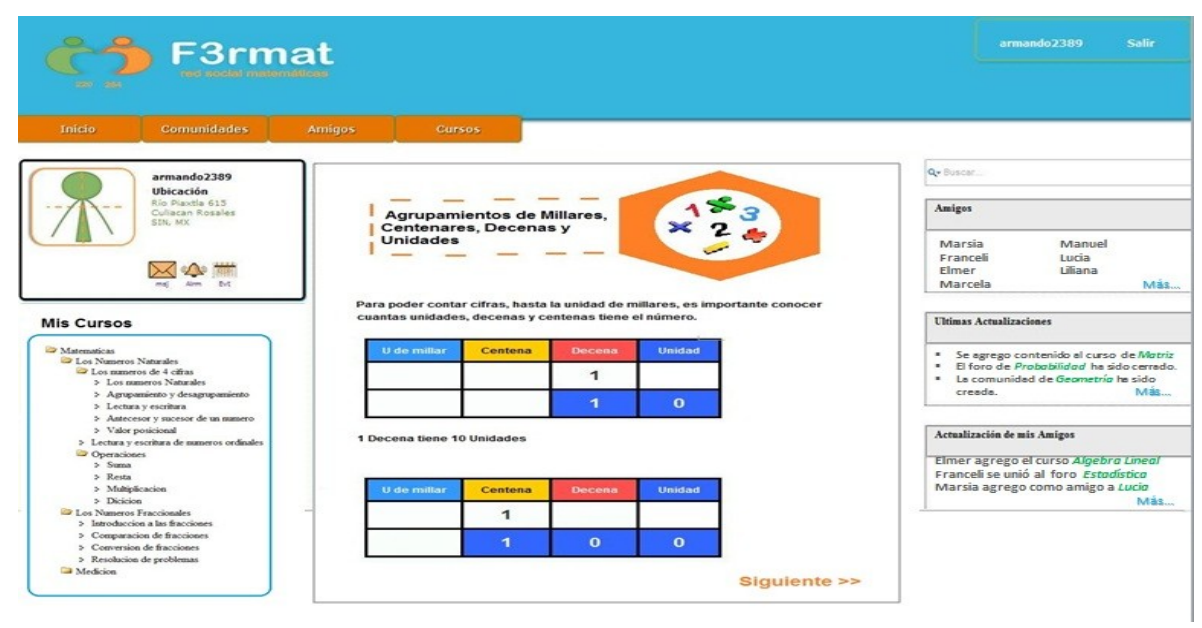

Fig. 6. Displayed Course in Fermat.

Later, the course was browsed by the students (Figure 6). 
At the end, students answered tests, which updated their sub-tree of knowledge, and the intelligent tutor showed them new information on the topics where the student presented problems.

\section{Conclusions}

Social networks are a tool where users can find a meeting space, making promoting a cooperative attitude of cooperation. Adding an Intelligent Tutoring System to a Social Network helped the teacher with the teaching process in order for students to gain meaningful learning. The actual results show that an Intelligent Social Network for Learning Mathematics can assist children to achieve better results in a context of traditional or formal education.

\section{References}

1. Aced, C.: Redes Sociales en una semana. Barcelona, PAPF, G. (Ed.) (2000)

2. Boyd, D. \& Ellison, N. B.: Social Network Sites: Definition, History, and Scholarship. Journal of Computer-Mediated Communication, 13 (2007)

3. Calvo Muñoz.: Networking, Uso práctico de las redes sociales. Madrid, M. ESIC (Ed.) (2009)

4. Graf, S., Rita Viola, S., \& Leo, T.: Representative characteristics Of Felder-Silverman Learning Styles: An Empirical Model. In: Proceedings of CELDA 2006, IADIS Int. Conf. on Cognition and Exploratory Learning in Digital Age. IADIS Press pp. 235-242 (2006)

5. Günel, K.: Intelligent Tutoring Systems: Conceptual Map Modeling. LAMBERT Academic Publishing (2010)

6. Kort, B., Reilly, R., \& Picard, R. W.: An Affective Model of Interplay Between Emotions and Learning: Reengineering Educational Pedagogy_Building a Learning Companion. In: Proceedings of the IEEE International Conference on Advanced Learning Technologies (ICALT '01). IEEE Computer Society, pp.43 (2001)

7. Liccardi, I.; Ounnas, A.: Pau, R.; Massey, E.; Kinnunen, P.; Lewthwaite, S.; Midy, M.-A. \& Sarkar, C.: The role of social networks in students' learning experiences SIGCSE Bull., ACM, vol. 39, pp. 224-237 (2007)

8. Mockup Builder @ copyright 2011. http://mockupbuilder.com/App (2011)

9. Patro, B.: Utilización de la Web 2.0 para aplicaciones educativas en la U.N.V.M. Eduvin. México, D.F. (2010)

10. Secretaria de Educación Pública. Enlace boletín informativo. Consultado el: 29 de agosto de 2010 ] http://enlace.sep.gob.mx/ba/docs/boletin enlaceba2010.pdf (2010)

11. Stankov, S., Glavinic, V., Rosic M.: Intelligent Tutoring Systems in E-Learning Environment: Design, Implementation and Evaluation. Information Science Reference (2011)

12. Wenger, E. Comunidades de práctica. Aprendizaje, significado e identidad, UOC (2001)

13. Ekman P, Oster,H.: Facial expressions of emotion. Annual Review of Psychology, vol. 30, pp. 527-554 (1979)

14. Pudil P, Novovičová J, Kittler J.: Floating search methods in feature selection. Pattern Recognition Letters, 15(11) (1994)

15. Sean, M.: The Mathematical Carrer of Pierre de FERMAT. Princenton University Press (1994) 